\title{
The activity of daily living (ADL) subgroups and health impairment among Chinese elderly: a latent profile analysis
}

\author{
Yangchang Zhang ${ }^{1 \dagger}$, Yang Xiong ${ }^{2 \dagger}$, Qiuhua Yu ${ }^{3}$, Shisi Shen ${ }^{1,4}$, Li Chen $^{5}$ and Xun Lei ${ }^{*^{*}}$
}

\begin{abstract}
Background: Disability in aged people became one of the major challenges in China due to the acceleration of population aging. Nevertheless, there were limited methods to appropriately discriminate the degree of combined basic activity of daily living (BADL) and instrumental activity of daily living (IADL). The present study explored an empirical typology of the activity of daily living (ADL) and its association with health status among the elderly in China.

Methods: Data throughout the Chinese Longitudinal Healthy Longevity Survey (CLHLS) was retrieved and Latent profile analysis (LPA) was conducted to identify the subgroups of ADL for included elderly subjects. Multinomial regression was performed to detect the effect of identified characteristics with ADL subgroups, and the restricted cubic spine was drawn to show the changes in the relationship between age-specific ADL disability and BMI.

Results: The overall participants ( $n=8108$ ) were divided into three ADL classes by LPA - 'no BADL limitation-no IADL limitation' (Class one, $n=6062,75 \%$ ), 'no BADL limitation- IADL impairment' (Class two, $n=1526,19 \%)$, and 'BADL impairment- IADL impairment' (Class three, $n=520,6 \%)$. Compared with the participants in Class one, the oldest-old, living without spouse, lacking of exercise, short in social activities, having experience of falls, having comorbidity of diabetes, heart disease, stroke, decreased cognitive function, depression symptom were highly associated with Class two and Class three. Additionally, malnutrition and asthma were associated with combined BADL/IADL impairment (Class three), while illiteracy was only associated with IADL impairment (Class two). Furthermore, a statistically significant U-shape association was detected between age and BADL/IADL disability (Class three vs. Class two) as well as BMI and BADL/IADL disability (Class three vs. Class one). The elderly aged 80-90 with IADL impairment were less likely to evolve into combined BADL/IADL impairment, and the elderly who were underweight or obese may have higher risk of combined BADL/IADL impairment.
\end{abstract}

Conclusion: A novel functional assessment was explored based on LPA, by which elderly people could be classified into three distinct classes of combined BADL/IADL. The predictors identified with particular IADL/BADL classes could draw early attention to the onset of functional disability and enlighten targeted interventions to address consequent problems of aged people.

Keywords: ADL, IADL, Disability, Impairment

\footnotetext{
*Correspondence: leixun521@163.com

${ }^{\dagger}$ Yangchang Zhang and Yang Xiong contributed equally to this work. 'Research Center for Medicine and Social Development, Collaborative Innovation Center of Social Risks Governance in Health, School of Public Health and Management, Chongqing Medical University, Chongqing, China Full list of author information is available at the end of the article
}

C C The Author(s). 2021 Open Access This article is licensed under a Creative Commons Attribution 4.0 International License, which permits use, sharing, adaptation, distribution and reproduction in any medium or format, as long as you give appropriate credit to the original author(s) and the source, provide a link to the Creative Commons licence, and indicate if changes were made. The images or other third party material in this article are included in the article's Creative Commons licence, unless indicated otherwise in a credit line to the material. If material is not included in the article's Creative Commons licence and your intended use is not permitted by statutory regulation or exceeds the permitted use, you will need to obtain permission directly from the copyright holder. To view a copy of this licence, visit http://creativecommons.org/licenses/by/4.0/. The Creative Commons Public Domain Dedication waiver (http://creativecommons.org/publicdomain/zero/1.0/) applies to the data made available in this article, unless otherwise stated in a credit line to the data. 


\section{Background}

Aging of population, giving rise to the prevalence of chronic diseases, financial burden and labor shortage, emerging as public health concerns, has caused a considerable concern and become a great challenge to the public health in China [1]. Life expectancy at birth of Chinese has increased from 71.8 to 74.5 years among male and 76.9 to 79.9 years among female. However, it was unoptimistic that the healthy life expectancy of Chinese was documented from 64.5 to 66.6 years for males and 67.5 to 69.7 years for females during2013to 2017 [2]. World Health Organization (WHO) reported that the healthy life expectancy would be more significant than the average life expectancy as the healthy life expectancy has counted in the growth trend of the average life expectancy and chronic disease burden [3]. Meanwhile, the independent physical and cognitive ability were considered as key components of geriatric healthy life expectancy to fulfill the successful aging.

Functional ability is the capacity of the individual to live and participate in social activities depending on his own intention and preference with significant meaning [4]. An investigation on senior people in China indicated that the overall functional disability rate was up to $41.0 \%$, with age-specific rates as $6.9,23.6$ and $42.7 \%$ for respondents aged 65-79, 80-89 and 90-99, respectively [5]. The functional ability of the elderly was usually measured with the basic ADL (BADL) and instrumental ADL (IADL). The BADL was one of the most commonly used criteria, covering basic self-care ability like bathing, dressing, eating and indoor activities [6]. In order to assess the ADL of the elderly in modern society, Lawton et al. designed the IADL scale, which represented individual's adaption to surrounding environment, such as making calls, shopping, cooking and doing housework [7].

Given BADL/IADL has been widely demonstrated to be associated with functional ability, identifying the specific profile of BADL/IADL was an important premise to understand and discriminate the functional heterogeneity among elder people [8]. Having said that, previous studies showed that discriminating functional limitation in older adults was still confusing and obscure, with roughly extensive categories or unreasonable merge of evaluating items [9-12]. Misclassification of functional limitation might be partially attributed to inappropriate definition of cut-points for BADL/IADL in some specific context.

Latent profile analysis (LPA) is an individual-centered algorithm, which can confirming the internal association with indiscrete manifest variables and classify individuals into common profiles $[13,14]$. Unobserved heterogeneity in BADL/IADL will be examined and identified by LPA in which case an optimized multidimensional BADL/IADL will be constructed rather than conventional ways.
Meanwhile, previous studies indicated that BADL/IADL was associated with socio-demographics, physical/mental conditions and health-related actions [15-21], which need to be adjusted when exploring BADL/IADL risk among the elderly.

The present study was aiming to (1) explore BADL/ IADL subgroups among the elderly by LPA and identify the difference therein, and (2) detect the association between functional limitation subgroups and characteristics of personal life and health status that help explain the heterogeneity of BADL/IADL.

\section{Methods}

\section{Data source and participants}

The data set used in the present study was retrieved from the Chinese Longitudinal Healthy Longevity Survey (CLHLS), which was carried out by Chinese Center for Disease Control and Prevention and directed by the Center for Healthy Aging and Development Studies at Peking University and Duke University. The CLHLS so far has launched eight waves of survey in 1998, (baseline)2000, 2002, 2005, 2008, 2011, 2014 and 2018, respectively. The overall sample was recruited across 23 provinces covering approximately $85 \%$ of China's total population, and about half of the cities/counties in each province were selected as primary survey units. In that case, the CLHLS survey was deemed as the first largest longitudinal survey regarding the elderly in developing countries [22]. Participants in CLHLS were recruited by a targeted random sampling process, by which investigators firstly recruit an eligible centenarian interviewee in sampled city/county, and then matched a nonagenarian, aoctogenarian and three elders aged 65-79 nearby in the same street, village or town. The age and sex participants aged 65-99 were randomly predefined to ensure the comparability with the centenarians who were randomly coded [23]. The survey content of CLHLS participants included personal mental and physical health, lifestyle, family structure relationship and health care. CLHLS database was recognized to be of high quality because it had a robust results of reliability/validity testing, little missing data and a high response rate [24]. More information of CLHLS was detailed at: http:// www.icpsr.umich.edu/icpsrweb/NACDA/studies/36179.

In order to reflect the latest classification of BADL/ IADL for the elderly people in China, CLHLS participants aged 65 years old and above in the wave of the survey in 2018 were included in our analyses, while those with missing data, dementia, or elder than 105 were excluded. Accordingly, 8108 elderly individuals were selected in the present study.

\section{Assessment of BADL/IADL}

BADL were measured with the following six subscales -(1) Bathing; (2) Dressing; (3) Toileting; (4) Indoor 
moving; (5) Continence of defecation; (6) Eating. Each item was scored from 1 to 3 (1 score representing complete independence; 2 scores representing partially dependence; 3 scores representing complete dependence). The more scores the respondents obtained, the higher BADL dependence they would be. IADL were rated with eight questions- (1) Can you visit your neighbors by yourself? (2) Can you go shopping by yourself? (3) Can you cook a meal by yourself when necessary? (4) Can you wash clothes by yourself when necessary? (5) Can you walk a kilometer at a time by yourself? (6) Can you lift a weight of $5 \mathrm{~kg}$, such as a heavy bag of groceries? (7) Can you continuously squat and stand up three times? (8) Can you take public transportation by yourself? Item were rated on a three-point scale ranging from 1 (Complete independence) to 3 (complete dependence). The more scores respondents obtained in B- and I- ADL assessment, the higher functional dependence they would have and need more external care/support from the family members or nursing staff. Previous evidence also showed that BADL and IADL could be independent indicators to effectively predicate functional disability among the elderly [25-27]. In addition, Spector et al. argued that a multidimensional structured BADL measurement could be more targeted to older people in need of nursing, and it would be feasible and practical to combine IADL into BADL measurement [28]. The CLHLS sample in 2018 showed a good internal consistency in BADL/IADL with the Cronbach's a of 0.818 , and participants were defined as functional impairment when the "complete dependence" were identified with at least one item in the BADL or IADL scales.

\section{Coding of basic characteristics and health indicators}

Basic characteristics were converted into categorical variables and digitally coded, including age (aged $65-79=0$, aged $80-105=1$ ), sex (female $=0$, male $=1$ ), marital status (living without spouse $=0$, living with spouse $=1$ ), education background (uneducated $=0$, educated $=1$ ), having physical exercises recently (no $=0$,yes $=1$ ), having social activities recently $($ no $=0$,yes $=1)$, place of residence (urban $=0$, rural $=1$ ). Health variables, referring to the physical indicators (BMI and comorbidity status) and mental indicators (cognitive function and depression symptoms), were collected via self-reports and objective measurement. Chinese version of the Mini Mental State Examination (MMSE) was used to evaluate the global cognitive function. MMSE has four dimensions of cognitive orientation, calculation, recall and language capacity, with a total of 24 items scoring from 0 to 30 , and the higher scores indicate a higher level of dependence for the respondents [21]. The elderly who obtained 24 scores and above were defined as "normal cognitive function", while those scored less than 24 were evaluated to be "cognitive impairment" [29]. The 10-item Center for Epidemiologic Studies Short Depression Scale (CESD) was adopted to measure the depression symptom, scoring from 0 to 30 with a cutoff point of 10 , to distinguish normal and depressive groups [30]. BMI was calculated as weight $(\mathrm{kg})$ /height $\left(\mathrm{m}^{2}\right)$. Weight status was categorized into four types, namely, underweight (BMI < $\left.18.5 \mathrm{~kg} / \mathrm{m}^{2}\right)$, normal weight $\left(18.5 \mathrm{~kg} / \mathrm{m}^{2} \leq \mathrm{BMI}<24 \mathrm{~kg} / \mathrm{m}^{2}\right)$, overweight $\left(24 \mathrm{~kg} / \mathrm{m}^{2} \leq \mathrm{BMI}<28 \mathrm{~kg} / \mathrm{m}^{2}\right)$, and obese $(\geq 28$ $\left.\mathrm{kg} / \mathrm{m}^{2}\right)$. Comorbidities, such as hypertension, diabetes, heart disease, stroke, asthma and cancer, were logged through selfreports, as well as experience of falls [31].

\section{Data analysis}

Descriptive analysis and statistical inference were conducted using Stata 16.0, and LPA were fitted using Mplus 7.4. The continuous variables were described using mean \pm standard deviation $(\mathrm{SD})$ and converted into the categorical variable, and then all the categorical variables were presented using number and proportion (\%). LPA was adopted to identify the potential class by BADL/IADL scores, and participants were divided into the class with an estimated LPA proportion via the homogeneity over the questionnaire responses. Each latent class was gradually allowed entering in the LPA model at a time after being tested and fitted with the previous class. The procedure of model fitting and algorithm iteration ended up when the $k$ latent class was involved and the comparison with the $k-1$ prior latent class was completed. Maximum likelihood estimation (MLE) was adopted to run the algorithm iteration at two stages - (1) set a starting value as zero to estimate and achieve maximum value, and (2) repeatedly estimated maximum value based on the value in the last step until the final one met the initially set aggregation standard [32].

The best latent classes was finalized when the test values of Akailke's Information Criterion (AIC), Bayesian Information Criterion (BIC) and sample size-adjusted BIC (aBIC) reached a relative minimum [33-35]. Bootstrap Likelihood Ratio Test (BLRT) and Lo-MendellRubin (LMR) were performed to compare differential distribution of log likelihood ratio between nested models, and statistical significance $(P<0.05)$ implied the $k$-class model was better than the $k-1$ model $[36,37$. Entropy, varying between 0 and 1,indicated a more accurate classification when the value was getting close to 1. Lubke and Muthén pointed that entropy below 0.60 meant that $20 \%$ of individual were misclassified, while above 0.80 meant that $90 \%$ of individuals were precisely classified [36]. Therefore, functional ability of the elderly was classified into three subgroup based on fitted indices, namely, Class one ('no BADL limitation-no IADL limitation', $n=6062$ ), Class two ('no BADL limitation- 
IADL impairment', $n=1526$ ), and Class three ('BADL impairment-IADL impairment', $n=520$ ).

Univariate analyses of categorical variables were processed with Chi-square test and Fisher's exact test. Multinomial logistic regression was performed to test the association between every latent class detected by LPA and any other variables with the reference of Class one. Restricted cubic spines with three knots at the 10th, 50th, 90th percentiles were used to flexibly fit the ageBADL/IADL association and BMI-BADL/IADL association with the odds ratio (OR) and 95\% confidence interval (CI).

\section{Results}

\section{Basic characteristics}

A total of 8108 participants were recruited in our study. As shown in Table 1, the average age of the participants was $82.46 \pm 11.01$ and $53.03 \% \quad(n=4300)$ of participants were female. Participants living in urban areas, being educated and living with spouse accounted for $58.76 \%$ ( $n=$ $4764), 57.84 \%(n=4690)$ and $47.13 \%(n=3821)$, respectively. There were $36.36 \%(n=2948)$ of participants taking physical exercises, but only $16.56 \%(n=1343)$ of participants had social activities recently. The measure of BMI showed that $51.60 \%(n=4184)$ of subjects were normal, followed by overweight $(25.44 \%, n=2063)$, obesity $(8.72 \%, n=707)$ and underweight $(14.23 \%, n=1154)$. Participants with the comorbidities of hypertension, diabetes, heart disease, stroke, asthma and cancer were respectively $44.63 \%(n=3619), 11.10 \% \quad(n=900), 17.96 \%$ $(n=1456), \quad 10.80 \% \quad(n=876)$ and $1.54 \% \quad(n=125)$, and $21.46 \%(n=1740)$ of the subjects reported to have fallen down. MMSE test showed that $78.48 \%(n=6363)$ of the subjects were declined in cognition, and CES-D test showed that $26.63 \%(n=2159)$ of subjects had depression symptoms. In addition, the average of combined BADL/ IADL was $18.9 \pm 6.6$.

\section{Latent classification of BADL/IADL}

Table 2 showed the analyses of BADL/IADL profiles for the participants. AIC, BIC and aBIC, testing the goodness of fit, were decreasing continuously when classes were gradually taken in the model. Entropy, ranging between 0.97 and 0.98 , showed an optimal fitting with five models. BLRT were highly significant for 2-, 3-, 4-class model, and LMR indicated that the posterior model (3and 4-class) were better than the previous model. In summary, 2-class model was firstly excluded because of inferior model fitting and higher AIC and BIC. LMR of 5 -class model was not better than the 4-class model $(P=$ 0.556 ), and the size of two clusters in 4-class model were only 4 and $3 \%$, therefore, 5 -class LPA model was subsequently excluded. 4-class model was similar in cluster distribution with 3-class model, but the 3-class model was more concise. Eventually, 3-class model was considered to be the best according to the parsimonious principle. Figure 1 showed the pattern of the 3-class solution of BADL/IADL.

Table 3 presented the estimation of item response mean of BADL/IADL subtypes for each class. Class one, with the largest size $(n=6062,75 \%)$, had a low item response mean in both BADL and IADL (BADL mean= 1.00 , ranging from 1.001 to 1.039 ; IADL mean $=1.184$, ranging from 1.015 to 1.401 ), and it was labeled as 'no BADL limitation-no IADL limitation'. Class two ( $n=$ 1526, 19\%) had a low item response mean in BADL (mean=1.131, ranging from 1.016 to 1.634 ) but a high item response mean in IADL (mean $=2.502$,ranging from 1.941 to 2.832 ), and it was therefore labeled as 'no BADL limitation-IADL impairment'. Class three $(n=520,6 \%)$ was relatively high in item response mean in both BADL and IADL (BADL mean=2.041, ranging from 1.292 to 2.861; IADL mean $=2.822$, ranging from 2.608 to 2.914), which was labeled as 'BADL impairment-IADL impairment'.

\section{Subgroup analyses}

As shown in Table 4, the majority of subjects in Class two were females $(n=951,62.32 \%)$ while half of subjects in Class one were males $(n=3021,49.84 \%)$. About 93.45\% of Class two were oldest-old people, as twice as it was in Class one $(n=2714,44.77 \%)$. Urban residents were dominated in Class three $(n=358,68.85 \%)$. The illiterate took the largest proportion in Class two $(n=$ $974,63.83 \%$ ) while the subjects living with a spouse was least in this class $(n=300,19.66 \%)$. The subjects having physical exercises $(n=52,10.00 \%)$ and social activities $(n=26,5.00 \%)$ took the smallest part in Class three. The elderly in Class three were high in underweight $(n=133$, $25.58 \%)$ and experiencing falls $(n=170,32.69 \%)$, and subjects in Class one were high in overweight and obesity $(n=2289,37.76 \%)$. Furthermore, the proportion of subjects having heart disease $(24.42 \%)$, stroke $(22.50 \%)$, asthma (16.15\%) and cancers (1.92\%) were largest in Class three, as well as the proportion of cognitive decline (66.54\%) and depression symptoms (39.81\%). Subjects with hypertension (45.65\%) and diabetes (11.55\%) accounted for the most in Class one. There was statistically significant difference among subjects in Class one, two and three in all the included variables except for having cancer.

\section{Multinomial logistic regression}

The Multinomial logistic regression was performed to calculate the OR of being a member of Class two or Class three versus Class one (Table 5). Logistic regression model showed that the elderly living in the rural area $(\mathrm{OR}=0.65,95 \% \mathrm{CI}=0.56-0.74)$, well-educated $(\mathrm{OR}=$ 
Table 1 Sample characteristics

Variables

Sex

Male

Female

Age (year)

65-79

80-105

\section{Place of residence}

Urban

Rural

Education

Uneducated

Educated

Marital status

Living without spouse

Living with spouse

Physical exercise (recently)

No

Yes

Social activity (recently)

No

Yes

BMI

underweight

normal

overweight

obese

Experience of falls

No

Yes

Hypertension

No

Yes

Diabetes

No

Yes

Heart disease

No

Yes

Stroke

No

Yes

Asthma

No

Yes
Mean $\pm S D / N(\%)$

3808 (46.97\%)

4300 (53.03\%)

$82.46 \pm 11.01$

3496 (43.12\%)

4612 (56.88\%)

4764 (58.76\%)

3344 (41.24\%)

3418 (42.16\%)

4690 (57.84\%)

4287 (52.87\%)

3821 (47.13\%)

5160 (63.64\%)

2948 (36.36\%)

$6765(83.44 \%)$

$1343(16.56 \%)$

$22.58 \pm 3.65$

1154 (14.23\%)

4184 (51.60\%)

$2063(25.44 \%)$

707 (8.72\%)

6368 (78.54\%)

$1740(21.46 \%)$

4489 (55.37\%)

3619 (44.63\%)

7208 (88.90\%)

$900(11.10 \%)$

6652 (82.04\%)

1456 (17.96\%)

7232 (89.20\%)

876 (10.80\%)

7324 (90.33\%)

784 (9.67\%) 
Table 1 Sample characteristics (Continued)

\begin{tabular}{lc}
\hline Variables & Mean $\pm S D / N(\%)$ \\
\hline Cancer & $7983(98.46 \%)$ \\
No & $125(1.54 \%)$ \\
Yes & $25.9 \pm 5.5$ \\
MMSE & $6363(78.48 \%)$ \\
Total score & $1745(21.52 \%)$ \\
Normal & \\
Cognitive decline & $7.5 \pm 4.2$ \\
Depression & 5949 (73.37\%) \\
Total score & $2159(26.63 \%)$ \\
Normal & $6.6 \pm 1.7$ \\
Having depression symptoms & $943(11.63 \%)$ \\
BADL & $12.3 \pm 5.4$ \\
BADL disability & 3186 (39.29\%) \\
IADL & $18.9 \pm 6.6$ \\
IADL disability & 3245 (40.02\%) \\
BADL/IADL & \\
BADL/IADL disability &
\end{tabular}

$0.84,95 \% \mathrm{CI}=0.72-0.98)$, living with spouse $(\mathrm{OR}=0.48$, $95 \% \mathrm{CI}=0.41-0.57)$, having physical exercises $(\mathrm{OR}=0.39$, $95 \% \mathrm{CI}=0.34-0.46)$ and taking social activities $(\mathrm{OR}=0.45$, $95 \% \mathrm{CI}=0.34-0.58)$ were less likely to be allocated into Class two. Furthermore, subjects who were oldest-old ( $\mathrm{OR}=8.26$, $95 \% \mathrm{CI}=6.58-10.38)$, suffering from diabetes $(\mathrm{OR}=1.35$, $95 \% \mathrm{CI}=1.06-1.72)$, heart disease $(\mathrm{OR}=1.27$, 95\% $\mathrm{CI}=1.05-$ $1.52)$, stroke $(\mathrm{OR}=1.72,95 \% \mathrm{CI}=1.38-2.15)$, falls $(\mathrm{OR}=1.58$, $95 \% \mathrm{CI}=1.36-1.85)$, cognitive impairment $(\mathrm{OR}=3.79,95 \% \mathrm{CI}=$ $3.26-4.40)$ and depression symptoms $(\mathrm{OR}=1.24,95 \% \mathrm{CI}=$ 1.07-1.44) were more likely to be assigned into Class two.

Aging at 80 and above $(\mathrm{OR}=4.55,95 \% \mathrm{CI}=3.22-6.44)$, being underweight $(\mathrm{OR}=1.34,95 \% \mathrm{CI}=1.03-1.73)$, being obese $(\mathrm{OR}=1.57,95 \% \mathrm{CI}=1.06-2.32)$, experiencing falls (OR=1.71, 95\% CI=1.37-2.15), having comorbidities of diabetes $(\mathrm{OR}=1.51,95 \% \mathrm{CI}=1.06-2.16)$, heart disease $(\mathrm{OR}=1.67,95 \% \mathrm{CI}=1.27-2.18)$, stroke $(\mathrm{OR}=3.55,95 \%$ $\mathrm{CI}=2.66-4.73)$, asthma $(\mathrm{OR}=1.56,95 \% \mathrm{CI}=1.15-2.12)$, cognitive impairment ( $\mathrm{OR}=9.57,95 \% \mathrm{CI}=7.61-12.03)$ and depression symptoms $(\mathrm{OR}=1.33,95 \% \mathrm{CI}=1.07-1.65)$ were positively associated with the allocation into Class three, while living in rural area $(\mathrm{OR}=0.47,95 \% \mathrm{CI}=0.37-$ 0.59), living with spouse ( $\mathrm{OR}=0.44,95 \% \mathrm{CI}=0.34-0.58)$, having physical activities $(\mathrm{OR}=0.19,95 \% \mathrm{CI}=0.14-0.27)$ and social activities $(\mathrm{OR}=0.36,95 \% \mathrm{CI}=0.23-0.57)$ were negatively associated with the allocation into Class three.

Figure 2 showed a significant U-shape association $(P<$ 0.001 ) between age and IADL impairment (Class three) compared to BADL impairment (Class two), and Fig. 3 showed a significant U-shape relationship $(P<0.001)$ between predicted BMI and BADL/IADL impairment (Class three vs. Class one).

\section{Discussion}

The present study adopted LPA to explore an efficient measurement to identify the classes of BADL/IADL in the elderly in order to discriminate status of functional impairment. Three latent classes, including 'no BADL

Table 2 Fit indices of latent class analysis on ADL subtypes

\begin{tabular}{lllllllll}
\hline Model & K & AIC & BIC & aBIC & Entropy & LMR & BLRT & Class Probability \\
\hline 1 & 28 & $182,235.96$ & $182,431.98$ & $182,343.02$ & - & - & - & 1 \\
2 & 43 & $120,223.44$ & $120,524.47$ & $120,387.83$ & 0.97 & 0.023 & $<0.001$ & $0.78 / 0.22$ \\
3 & 58 & $85,654.45$ & $86,060.49$ & $85,876.17$ & 0.98 & $<0.001$ & $<0.001$ & $0.19 / 0.75 / 0.06$ \\
4 & 73 & $73,010.91$ & $73,521.96$ & $73,289.98$ & 0.99 & $<0.001$ & $<0.001$ & $0.18 / 0.75 / 0.04 / 0.03$ \\
5 & 98 & $60,971.16$ & $61,587.22$ & $61,307.57$ & 0.98 & $<0.556$ & $<0.001$ & $0.18 / 0.62 / 0.13 / 0.04 / 0.02$ \\
\hline
\end{tabular}

$K$ freedom of model, AIC Akaike Information Criterion, BIC Bayesian Information Criterion, aBIC adjusted Bayesian Information Criterion, LMR Lo-Mendell-Rubin likelihoodratio test; BLRT Bootstraplikelihood ratio test 


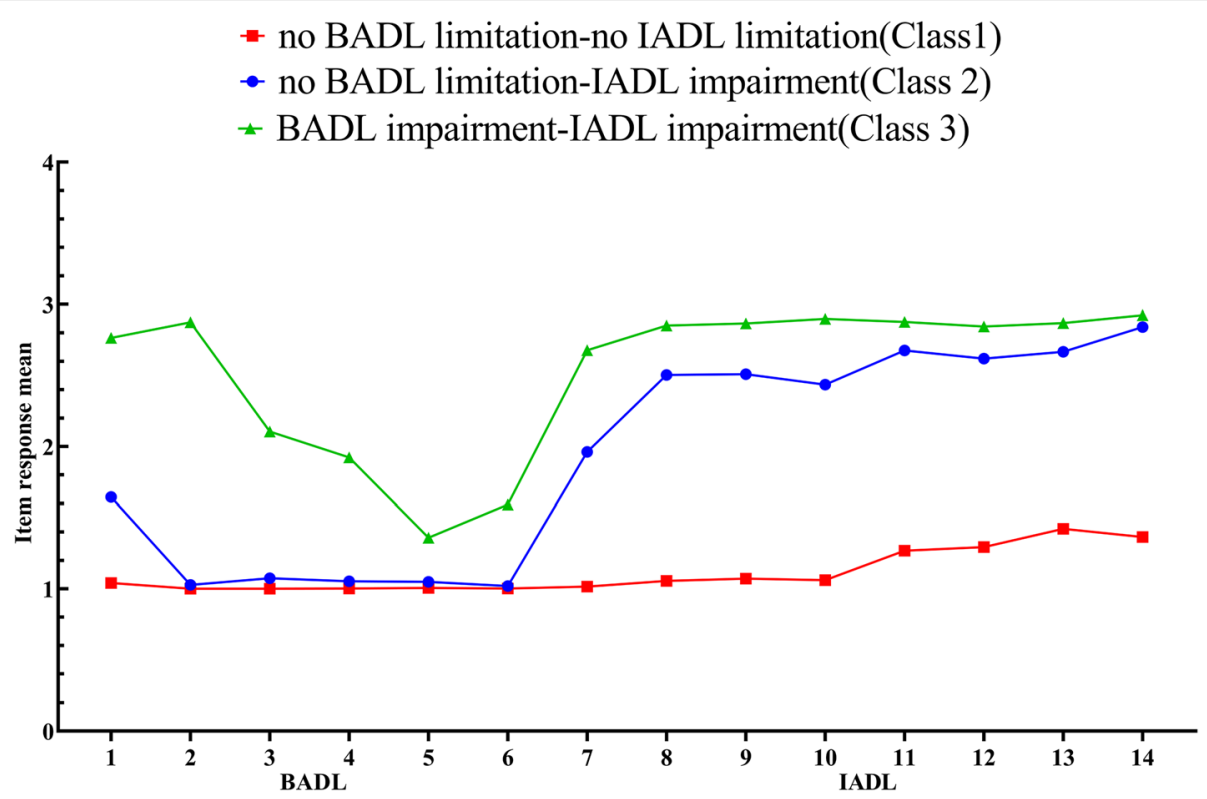

Fig. 1 Distribution of the mean BADL and IADL scores for each of the items by subgroup. Note. BADL: basic activities of daily living; IADL: instrumental activities of daily living

limitation-no IADL limitation'(Class one), 'no BADL limitation-IADL impairment'(Class two), 'BADL impairment-IADL impairment' (Class three), were constructed based on the item response means.

LPA clustering in our study showed that the BADL/ IADL dependence (Class three) was about 6\%, and IADL impairment was 19\% (Class two), and $75 \%$ of participants was assigned into the almost functional independence (Class one). In contrast, the proportion of BADL impairment were lower in the studies with American population (18\%) and British population (28\%), while the proportion of IADL impairment was higher in the

Table 3 Item response mean and standard errors in latent profile analysis of ADL

\begin{tabular}{|c|c|c|c|c|c|c|c|c|}
\hline \multirow[t]{3}{*}{ Item } & \multicolumn{2}{|c|}{ Class One } & \multicolumn{2}{|c|}{ Class Two } & \multicolumn{2}{|c|}{ Class Three } & \multicolumn{2}{|c|}{ Total sample Mean (SD) } \\
\hline & Mean & SE & Mean & SE & Mean & SE & Mean & SD \\
\hline & \multicolumn{2}{|c|}{$n=6062(75 \%)$} & \multicolumn{2}{|c|}{$n=1526(19 \%)$} & \multicolumn{2}{|c|}{$n=520(6 \%)$} & \multicolumn{2}{|c|}{$n=8108(100 \%)$} \\
\hline$\overline{B A D L}$ & 1.001 & & 1.131 & & 2.041 & & & \\
\hline 1 & 1.039 & 0.003 & 1.634 & 0.025 & 2.736 & 0.025 & 1.260 & 0.634 \\
\hline 2 & 1.001 & 0.001 & 1.025 & 0.005 & 2.861 & 0.017 & 1.126 & 0.470 \\
\hline 3 & 1.001 & 0.001 & 1.062 & 0.007 & 2.001 & 0.030 & 1.077 & 0.319 \\
\hline 4 & 1.002 & 0.001 & 1.043 & 0.006 & 1.826 & 0.031 & 1.063 & 0.278 \\
\hline 5 & 1.006 & 0.001 & 1.041 & 0.006 & 1.292 & 0.024 & 1.030 & 0.189 \\
\hline 6 & 1.002 & 0.001 & 1.016 & 0.003 & 1.522 & 0.031 & 1.038 & 0.225 \\
\hline IADL & 1.184 & & 2.502 & & 2.822 & & & \\
\hline 1 & 1.015 & 0.002 & 1.941 & 0.028 & 2.608 & 0.035 & 1.291 & 0.668 \\
\hline 2 & 1.049 & 0.005 & 2.460 & 0.026 & 2.820 & 0.023 & 1.427 & 0.764 \\
\hline 3 & 1.066 & 0.005 & 2.474 & 0.028 & 2.842 & 0.021 & 1.444 & 0.782 \\
\hline 4 & 1.052 & 0.004 & 2.409 & 0.031 & 2.878 & 0.018 & 1.424 & 0.770 \\
\hline 5 & 1.249 & 0.008 & 2.667 & 0.018 & 2.852 & 0.020 & 1.618 & 0.829 \\
\hline 6 & 1.278 & 0.008 & 2.612 & 0.019 & 2.820 & 0.022 & 1.628 & 0.842 \\
\hline 7 & 1.401 & 0.009 & 2.666 & 0.016 & 2.846 & 0.019 & 1.731 & 0.842 \\
\hline 8 & 1.339 & 0.011 & 2.832 & 0.013 & 2.914 & 0.016 & 1.720 & 0.891 \\
\hline
\end{tabular}

Class one: 'no BADL limitation-no IADL limitation'; Class two:'no BADL limitation- IADL impairment'; Class three: 'BADL impairment- IADL impairment' 
Table 4 Difference among ADL types with included variables

\begin{tabular}{|c|c|c|c|c|}
\hline Variables & Class one & Class two & Class three & $P$ value \\
\hline Sex & & & & $<0.001$ \\
\hline Male & 3021 (49.84\%) & $575(37.68 \%)$ & $212(40.77 \%)$ & \\
\hline Female & $3041(50.16 \%)$ & $951(62.32 \%)$ & $308(59.23 \%)$ & \\
\hline Age (year) & & & & $<0.001$ \\
\hline $65-79$ & $3348(55.23 \%)$ & $100(6.55 \%)$ & $48(9.23 \%)$ & \\
\hline $80-105$ & $2714(44.77 \%)$ & $1426(93.45 \%)$ & $472(90.77 \%)$ & \\
\hline The place of residence & & & & $<0.001$ \\
\hline Urban & $3472(57.27 \%)$ & $934(61.21 \%)$ & $358(68.85 \%)$ & \\
\hline Rural & $2590(42.73 \%)$ & $592(38.79 \%)$ & $162(31.15 \%)$ & \\
\hline Education & & & & $<0.001$ \\
\hline Illiterate & $2146(35.40 \%)$ & $974(63.83 \%)$ & $298(57.31 \%)$ & \\
\hline Educated & $3916(64.60 \%)$ & $552(36.17 \%)$ & $222(42.69 \%)$ & \\
\hline Marital status & & & & $<0.001$ \\
\hline Living without spouse & $2644(43.62 \%)$ & $1226(80.34 \%)$ & $417(80.19 \%)$ & \\
\hline Living with spouse & $3418(56.38 \%)$ & $300(19.66 \%)$ & $103(19.81 \%)$ & \\
\hline Physical exercise (recently) & & & & $<0.001$ \\
\hline No & $3443(56.80 \%)$ & 1249 (81.85\%) & $468(90.00 \%)$ & \\
\hline Yes & 2619 (43.20\%) & $277(18.15 \%)$ & $52(10.00 \%)$ & \\
\hline Social activity (recently) & & & & $<0.001$ \\
\hline No & $4836(79.78 \%)$ & 1435 (94.04\%) & $494(95.00 \%)$ & \\
\hline Yes & $1226(20.22 \%)$ & 91 (5.96\%) & $26(5.00 \%)$ & \\
\hline BMI & & & & $<0.001$ \\
\hline underweight & $690(11.38 \%)$ & 331 (21.69\%) & $133(25.58 \%)$ & \\
\hline normal & $3083(50.86 \%)$ & 837 (54.85\%) & $264(50.77 \%)$ & \\
\hline overweight & 1725 (28.46\%) & $258(16.91 \%)$ & $80(15.38 \%)$ & \\
\hline obese & $564(9.30 \%)$ & $100(6.55 \%)$ & $43(8.27 \%)$ & \\
\hline Experience of falls & & & & $<0.001$ \\
\hline No & 4942 (81.52\%) & 1076 (70.51\%) & $350(67.31 \%)$ & \\
\hline Yes & $1120(18.48 \%)$ & 450 (29.49\%) & 170 (32.69\%) & \\
\hline Hypertension & & & & $<0.001$ \\
\hline No & 3295 (54.35\%) & 901 (59.04\%) & $293(56.35 \%)$ & \\
\hline Yes & 2767 (45.65\%) & 625 (40.96\%) & $227(43.65 \%)$ & \\
\hline Diabetes & & & & 0.037 \\
\hline No & $5362(88.45 \%)$ & 1385 (90.76\%) & $461(88.65 \%)$ & \\
\hline Yes & 700 (11.55\%) & 141 (9.24\%) & $59(11.35 \%)$ & \\
\hline Heart disease & & & & $<0.001$ \\
\hline No & $5012(82.68 \%)$ & 1247 (81.72\%) & $393(75.58 \%)$ & \\
\hline Yes & 1050 (17.32\%) & 279 (18.28\%) & 127 (24.42\%) & \\
\hline Stroke & & & & $<0.001$ \\
\hline No & $5482(90.43 \%)$ & 1347 (88.27\%) & $403(77.50 \%)$ & \\
\hline Yes & $580(9.57 \%)$ & 179 (11.73\%) & $117(22.50 \%)$ & \\
\hline Asthma & & & & $<0.001$ \\
\hline No & $5533(91.27 \%)$ & 1355 (88.79\%) & $436(83.85 \%)$ & \\
\hline Yes & $529(8.73 \%)$ & 171 (11.21\%) & $84(16.15 \%)$ & \\
\hline
\end{tabular}


Table 4 Difference among ADL types with included variables (Continued)

\begin{tabular}{|c|c|c|c|c|}
\hline Variables & Class one & Class two & Class three & $P$ value \\
\hline Cancer $^{a}$ & & & & 0.646 \\
\hline No & 5968 (98.45\%) & 1505 (98.62\%) & $510(98.08 \%)$ & \\
\hline Yes & $94(1.55 \%)$ & $21(1.38 \%)$ & $10(1.92 \%)$ & \\
\hline MMSE & & & & $<0.001$ \\
\hline Normal & 5407 (89.19\%) & $782(51.25 \%)$ & $174(33.46 \%)$ & \\
\hline Cognitive decline & 655 (10.81\%) & $744(48.75 \%)$ & $346(66.54 \%)$ & \\
\hline Depression & & & & $<0.001$ \\
\hline Normal & $4639(76.53 \%)$ & $997(65.33 \%)$ & $313(60.19 \%)$ & \\
\hline Having depression symptoms & $1423(23.47 \%)$ & $529(34.67 \%)$ & 207 (39.81\%) & \\
\hline
\end{tabular}

Class one: 'no BADL limitation-no IADL limitation'; Class two: 'no BADL limitation- IADL impairment'; Class three: 'BADL impairment- IADL impairment'. 'Fisher's exact test

American population U.S.A (17\%) and the British population $(28 \%)[38,39]$.

In line with previous evidence, age was a risk predictor for combined BADL/IADL impairment because of the age-related decline in body function and limitation in social activities [19]. The U-shape relation between age and functional impairment suggested that the elderly with IADL impairment was less likely to suffer the combined BADL/IADL impairment among aged 80-90 years. The possible reason is that the risk of having chronic diseases would also increase rapidly along with getting old, which may accelerate the ADL disability among people [40]. Meanwhile, this curve supported the view point of Hung saying that IADL impairment may increase the alertness of the elderly [39].

To our knowledge, favorable living surrounding may provide a healthier life to individuals. People living in urban area would more or less have better income, education and medical service than those in rural [41]. Zhang et al. found that inadequate access to healthcare was potential factor associated with functional limitation [42]. However, inconsistent clue was conversely detected

Table 5 Multinomial logistic regression on ADL subgroups

\begin{tabular}{|c|c|c|c|c|}
\hline \multirow[t]{2}{*}{ Variable $^{a}$} & \multicolumn{2}{|c|}{ Class Two } & \multicolumn{2}{|c|}{ Class Three } \\
\hline & $\overline{O R}$ & $95 \% \mathrm{Cl}$ & $\overline{O R}$ & $95 \% \mathrm{Cl}$ \\
\hline Sex (Female) & 0.90 & $0.77-1.05$ & 0.80 & $0.63-1.02$ \\
\hline Age (80-105) & $8.26^{* * *}$ & $6.58-10.38$ & $4.55^{* * *}$ & $3.22-6.44$ \\
\hline Residence (Rural) & $0.65^{* * *}$ & $0.56-0.74$ & $0.47^{* * *}$ & $0.37-0.59$ \\
\hline Education (Educated) & $0.84^{*}$ & $0.72-0.98$ & 1.22 & $0.96-1.56$ \\
\hline Marital status (living with spouse) & $0.48^{* * *}$ & $0.41-0.57$ & $0.44^{* * *}$ & $0.34-0.58$ \\
\hline Exercise (Yes) & $0.39^{* * *}$ & $0.34-0.46$ & $0.19 * * *$ & $0.14-0.27$ \\
\hline Social activity (Yes) & $0.45^{* * *}$ & $0.34-0.58$ & $0.36^{* * *}$ & $0.23-0.57$ \\
\hline \multicolumn{5}{|l|}{ BMI } \\
\hline underweight & 1.07 & $0.89-1.27$ & $1.34^{*}$ & $1.03-1.73$ \\
\hline overweight & 0.90 & $0.75-1.08$ & 0.79 & $0.59-1.07$ \\
\hline obese & 1.16 & $0.89-1.52$ & $1.57^{*}$ & $1.06-2.32$ \\
\hline Experience of falls (Yes) & $1.58^{* * *}$ & $1.36-1.85$ & $1.71^{* * *}$ & $1.37-2.15$ \\
\hline Hypertension (Yes) & 0.95 & $0.82-1.10$ & 0.98 & $0.78-1.22$ \\
\hline Diabetes (Yes) & $1.35^{*}$ & $1.06-1.72$ & $1.51^{*}$ & $1.06-2.16$ \\
\hline Heart disease (Yes) & $1.27^{*}$ & $1.05-1.52$ & $1.67^{* * *}$ & $1.27-2.18$ \\
\hline Stroke (Yes) & $1.72^{* * *}$ & $1.38-2.15$ & $3.55^{* * *}$ & $2.66-4.73$ \\
\hline Asthma (Yes) & 1.19 & $0.95-1.47$ & $1.56^{* *}$ & $1.15-2.12$ \\
\hline MMSE (Cognitive decline) & $3.79^{* * *}$ & $3.26-4.40$ & $9.57^{* * *}$ & $7.61-12.03$ \\
\hline Depression (Having depression symptoms) & $1.24^{* * *}$ & $1.07-1.44$ & $1.33^{* * *}$ & $1.07-1.65$ \\
\hline
\end{tabular}

${ }^{* * * *} P<0.001{ }^{* *} P<0.01{ }^{*} P<0.05$; Reference group: Class 1.OR: Odds ratio.95\%Cl: $95 \%$ Confidence Interval. Class one: 'no BADL limitation-no IADL limitation'; Class two: 'no BADL limitation- IADL impairment'; Class three: 'BADL impairment- IADL impairment' 


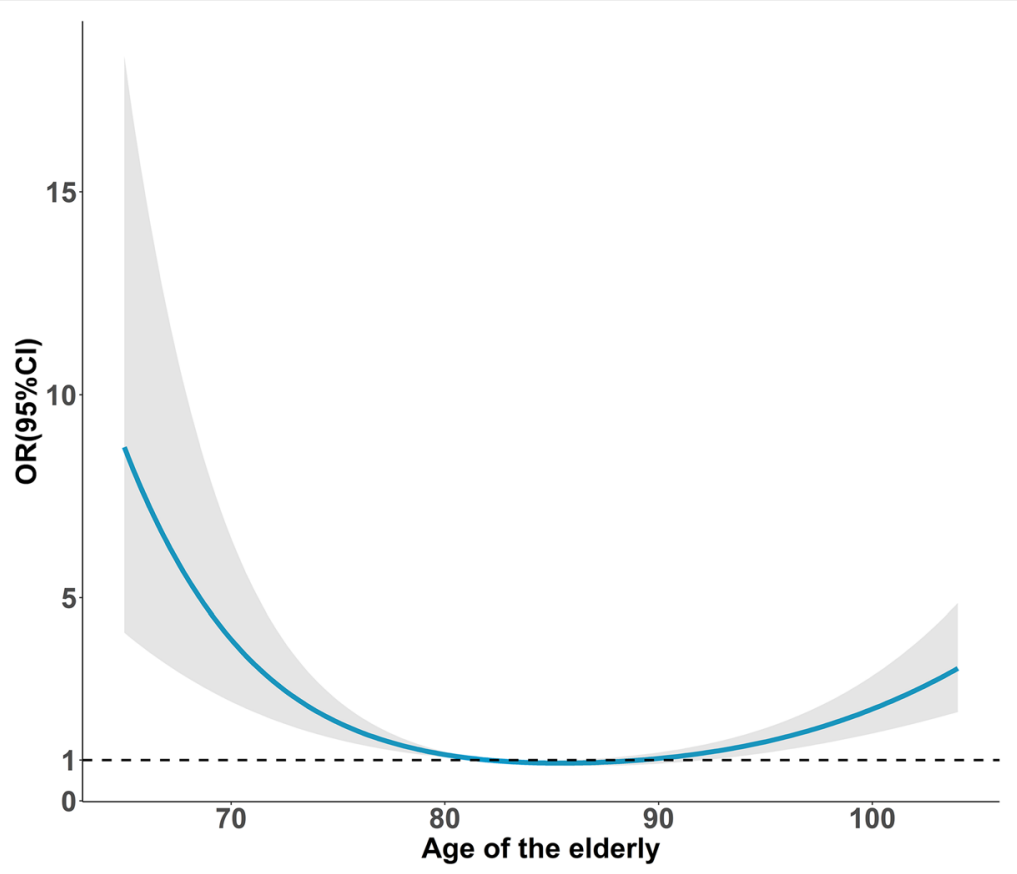

Fig. 2 Curvilinear association between ADL disability (Class three vs. Class two) and the age among the elderly. Note. Shading indicates $95 \%$ Cls. The reference point is 82 , after adjusting sex, fall experience, marital status, having exercise, social activities, residence place, having chronic disease, cognitive function and BMl

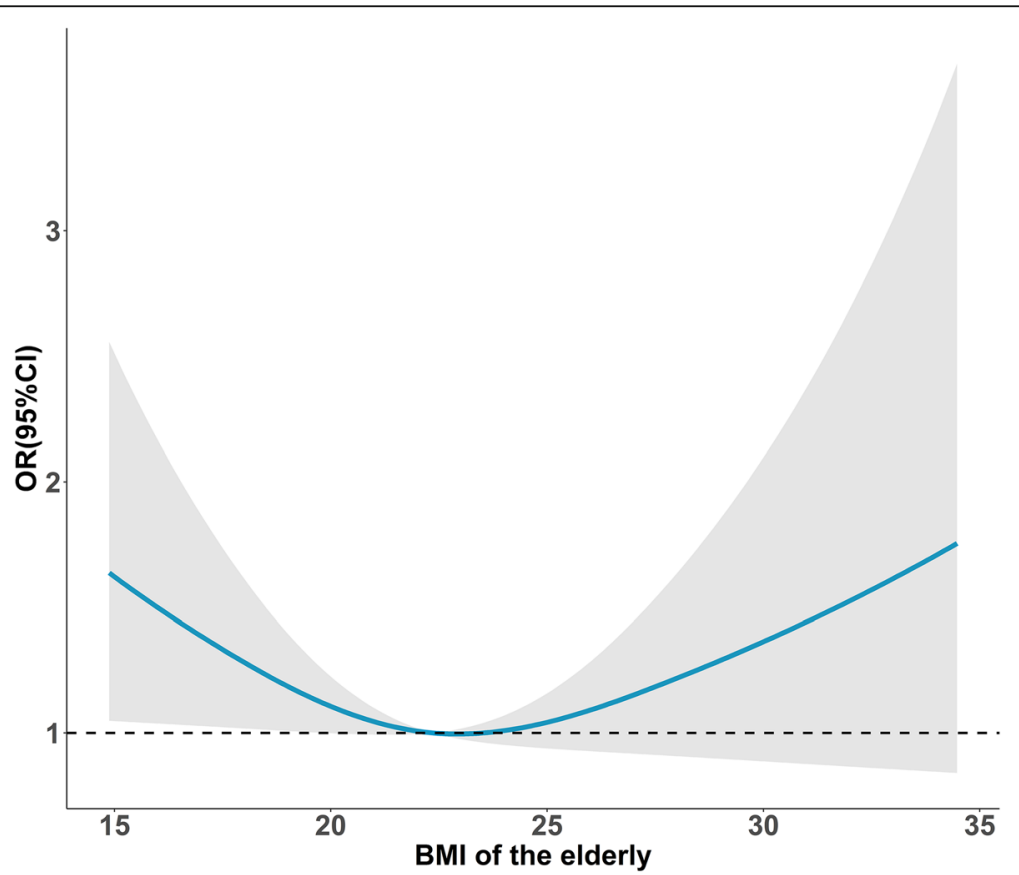

Fig. 3 Curvilinear association between ADL disability (Class three vs. Class two) and BMI among the elderly. Note. Shading indicates 95\% Cls. The reference point is 22, after adjusting age, sex, fall experience, marital status, having exercise, social activities, residence place, having chronic disease, cognitive function 
in our study, which showed that old people in Class two and Class three were more likely to live in urban place compared with those in Class one. It is because rural residents probably take more physical activities like farming and harvesting in China, which definitely do good to the upkeep of body function.

In addition, we found that receiving education was a protective factor in Class two. Likewise, previous studies showed that the educated elderly people had better health awareness, which was significantly associated with better IADL $[43,44]$. A possible reason is that the educated elderly may make better use of social support and timely seek medical care [43].

A significantly negative association between marital status and BADL/IADL impairment was basically consistent with a longitudinal study with Irish people [45], which argued that the spouse usually plays the role of caregivers particular when an elderly person has disease or functional dependence, and the ADL of the elderly would getting worse once lack of the company of the spouse [46].

Keeping moderate social activities and regular physical exercises were effective to postpone BADL/IADL disabilities [41]. According to the Activity Theory, human beings demand a sense of achievement and belonging within the social network, and the elderly were inclined to participant activities that will strengthen their social integration and adaptation [47, 48]. A cohort study in Japanese indicated that the elderly with functional disability were less engaged in community management and activities which implied that solitary status may lead to a decline of IADL function [49].

Compared with Class two, the elderly being underweight or obese were more likely to be assigned as Class three, and this association was not detected in Class one. The positive association between obese and high BADL impairment might be explained by an increasing likelihood of getting chronic diseases for the obese people which would further limit heir living function [50]. Meanwhile, underweight status was also verified to be associated with BADL impairment due to the decrement in bone mineral content and bone mineral density, which would cause a higher risk of osteoporosis and even fracture [51]. Experiencing falls were positively associated with BADL/IADL decline because the incidence of all-cause fracture will also increase among aged people who fell down [52] in line with Bahat's conclusion, BMI was not associated with Class two, which indicated that being obese may not be a risk for IADL [53]. Partially in fact, higher BMI sometimes reflects better living standards and medical resources that may benefit IADL function.

The present study found that the diabetes, heart disease, stroke were independent risk factors in Class one and Class three. A study in Poland revealed that multimorbidity was main risk factor for BADL disability and the pains caused by the diseases may limit the body movements and result in IADL disability [54]. The elderly with diabetes often have the diabetic complication with heart, which may evolve to heart failure [55]. In addition, the elderly always have some adverse symptoms and signs, like declined activity tolerance, increased heart rate or dyspnea, which may worsen BADL/IADL impairment [56].

Depression and cognitive impairment were independently associated with BADL or IADL difficulties in Class two and Class three. Ormel et al. suggested that depression symptom and functional limitation had a mutual reinforcement among the elderly overt time [57]. The previous reports illustrated that fatigue, poor sleep quality and anorexia could reduce treatments and preventions initiative for disability, and depressive patients were undermined their IADL function [58].

Cognitive function mirrored individual's mental status, which has interaction with physical dysfunction among age people. The reaction of external stimuli was reduced when a series of somatic diseases emerged, afterwards the cognitive damage would reversely influence the body function. Fisher et al. argued that cognitive impairment increased the risk of falling for the elderly [59]. Connolly et al. pointed out that cognitive impairment significantly decreased the function of IADL because of degenerative language and mobility [45]. Therefore, timely cognitive assessment plays an essential role in the chains between mental and physical health for the elderly.

There are several limitations that must be discussed. Firstly, the cross-sectional study limits the causality, and bi-directional relationship between healthy factors and BADL/IADL would be considered as well. Therefore, longitudinal study is in need to further explore and verify the mechanism. Secondly, recall bias was unavoidable due to the use of self-rated questionnaire. Thirdly, the subjects with missing values were excluded from analyses that will cause over- or under-estimate. And the Hawthrone effect, in which case the elderly might conceal poor performance of health and lifestyle, might disturb the risk estimate of functional disability. Finally, limited by the secondary data extraction, the hospitalization and economic data were not yet available.

\section{Conclusion}

BADL/IADL assessment was established using the cluster LPA. Three distinct classes of combined BADL/IADL among Chinese older people were identified. The largest group was Class one (no BADL limitation-no IADL limitation) for all item of BADL/IADL scales. Stroke and cognitive impairment of the oldest-old were highly 
associated with BADL/IADL difficulties in Class two (no BADL limitation-IADL impairment) and Class three (BADL impairment-IADL impairment). A remarkable U-shape association was detected between age and functional impairment as well as BMI and functional impairment. Targeted interventions should be initiated in terms of the major predictors that have significant effects on the BADL/IADL classes, and well designed longitudinal studies are in need to examine the reliability and validity of the outcomes.

\section{Abbreviations}

BMl: Body mass index; ADL: Activity of daily living; BADL: Basic activity of daily living; IADL: Instrumental activity of daily living; CES-D: Epidemiologic Studies Short Depression Scale; MMSE: Mini-Mental State Examination; CLHL S: Chinese longitudinal healthy longevity survey

\section{Acknowledgments}

Data used in this research were provided by the study entitled "Chinese Longitudinal Longevity Survey" (CLHLS) was jointly implemented by the Center for Healthy Aging and Development Studies of Peking University and Duke University. CLHLS is supported by funds from the U.S. National Institutes on Aging (NIA), China Natural Science Foundation, China Social Science Foundation, and UNFPA.

\section{Authors' contributions}

Conceptualization, $\mathrm{XL}$ and $\mathrm{YZ}$; Methodology, $Y X$ and $\mathrm{XL}$; Validation, $\mathrm{YX}$; Formal Analysis, YZ and LC and SS and QY; Writing-Original Draft Preparation, $Y Z$ and $Y X$; Writing-Review \& Editing, $X L$, SS and LC; Interpretation of data, $\mathrm{CL}$; Writing-revised Draft Editing and polishing, XL and LC All authors have read and approved the manuscript.

\section{Funding}

This research was funded by National Natural Science Foundation of China, grant number 71603034. It provided us with financial support in expert consultation and data analysis.

\section{Availability of data and materials}

The CLHLS questionnaires are available at https://sites.duke.edu/ centerforaging/programs/chinese-longitudinal-healthy-longevity-survey-clhls/ survey-documentation/questionnaires/. The full datasets used in this analysis are available from the corresponding author upon reasonable request.

\section{Ethics approval and consent to participate}

The datasets that support this article are publicly available from the project of the CLHLS. It was approved by research ethics committees of Peking University (IRB00001052-13074). The datasets analyzed during the current study are available online (http://opendata.pku.edu.cn/) from Peking University Open Research Data for researchers who meet the criteria for access to these de-identified data. No experimental interventions were performed.

\section{Consent for publication}

Not applicable.

\section{Competing interests}

The authors declare no conflict of interest.

\section{Author details}

${ }^{1}$ Research Center for Medicine and Social Development, Collaborative Innovation Center of Social Risks Governance in Health, School of Public Health and Management, Chongqing Medical University, Chongqing, China. ${ }^{2}$ Andrology lab / Department of urology, the West China Hospital, Sichuan University, Chengdu, China. ${ }^{3}$ Department of Nursing, Chongqing Medical University, Chongqing, China. ${ }^{4}$ The First School of Clinical Medicine, Chongqing Medical University, Chongqing, China. ${ }^{5}$ The School of Public Health, Peking University, Beijing, China.
Received: 11 August 2020 Accepted: 22 December 2020

Published online: 07 January 2021

\section{References}

1. Fang EF, Scheibye-Knudsen $M$, Jahn $\mathrm{HJ}$, et al. A research agenda for aging in China in the 21st century. Ageing Res Rev. 2015:24(Pt B):197-2.

2. Yin P, Qi J, Liu Y, Liu J, Li J, Zeng X. China disease burden research report 2005-2017. Chin Circul J. 2019;12:1145-54. In Chine.

3. World Health Organization. World Health Report 1997. Available online: https://www.who.int/whr/1997/en/. Accessed 5 June 2020.

4. World Health Organization. World report on ageing and health. Geneva: World Health Organization; 2015. p. 246

5. Deting $Y$. The comparing study on individual factors about Elder's ability of caring for themselves. J Beijing Admin College. 2017;1:86-91. In Chinese.

6. Katz SC, Ford AB, Moskowitz RW. B.a. Jackson, Jaffe, M. W. studies of illness in the aged. The index of ADL: a standardized measure of biological and psychosocial function. JAMA. 1963;185(12):914-9.

7. Lawton MP, Brody EM. Assessment of older people:self-maintaining and instrumental activities of daily living. Gerontologist. 1969;9(3):179.

8. Edjolo A, Dartigues JF, Pérès K, Proust-Lima C. Heterogeneous long-term trajectories of dependency in the elderly: the PAQUID cohort, a 22-year population-based study. J Gerontol A Biol Sci Med Sci. 2020;75:2396-403.

9. Contador I, Fernández-Calvo B, Rueda-Revé L, Olazarán J, Bermejo-Pareja F. Characterizing functional alterations in instrumental activities of dailyliving using latent class analysis: a population-based study (NEDICES). Aging Ment Health. 2020:24(1):41-8.

10. Ayis SA, Bowling A, Gooberman-Hill R, Ebrahim S. The effect of definitions of activities of daily living on estimates of changing ability among older people. Int J Rehabil Res. 2007;30(1):39-46.

11. Jette AM. How measurement techniques influence estimates of disability in older populations. Soc Sci Med. 1994;38(7):937-42.

12. Osler M, de Groot LC, Enzi G. Life-style: physical activities and activities of daily living. Euronut SENECA investigators. Eur J Clin Nutr. 1991;45(Suppl 3): 139-51.

13. Carragher N, Adamson G, Bunting B, McCann S. Subtypes of depression in a nationally representative sample. J Affect Disord. 2009;113(1-2):88-99.

14. Lanza ST, Rhoades BL. Latent class analysis: an alternative perspective on subgroup analysis in prevention and treatment. Prev Sci. 2013;14(2):157-68.

15. Arnau A, Espaulella J, Serrarols M, Canudas J, Formiga F, Ferrer M. Risk factors for functional decline in a population aged 75 years and older without total dependence: a one-year follow-up. Arch Gerontol Geriatr. 2016:65:239-47.

16. Backholer K, Wong E, Freak-Poli R, Walls HL, Peeters A. Increasing body weight and risk of limitations in activities of daily living: a systematic review and meta-analysis. Obes Rev. 2012;13(5):456-68.

17. Fried LP, Guralnik JM. Disability in older adults: evidence regarding significance, etiology, and risk. J Am Geriatr Soc. 1997;45(1):92-100.

18. Nascimento Cde M, Ribeiro AQ, Cotta RM, et al. Factors associated with functional ability in Brazilian elderly. Arch Gerontol Geriatr. 2012;54(2): e89-94.

19. Stuck AE, Walthert JM, Nikolaus T, Büla CJ, Hohmann C, Beck JC. Risk factors for functional status decline in community-living elderly people: a systematic literature review. Soc Sci Med. 1999:48(4):445-69.

20. Drumond Andrade FC, Guevara PE, Lebrão ML, de Oliveira Duarte YA, Santos JL. Sex differences in life expectancy and disability-free life expectancy among older adults in São Paulo, Brazil. Womens Health Issues. 2011:21(1):64-70.

21. Yi Z, Vaupel JW. Functional capacity and self-evaluation of health and life of oldest old in China. J Soc Issues. 2010:58(4):733-48.

22. Zeng Y, James W, Xiao Z, Zhang C, Liu Y. Sociodemographic and health profiles of the oldest old in China. Popul Dev Rev. 2002;28(2):251-73.

23. Zeng Y, Poston DL, Vlosky DA. Healthy longevity in China:demographic, socioeconomic, and psychological dimensions. Germany: Springer; 2008.

24. Zhang $H$, Wang $Y$, Wu D, Chen J. Evolutionary path of factors influencing life satisfaction among Chinese elderly: a perspective of data visualization. Int J Environ Res Public Health. 2018:3:35.

25. Li B, Liu J. The effect of health changes on self-reported quality of life of the elderly in China: fixed effects model analysis based on CLHLS data. Popul Econ. 2015;6:1-11 (In Chinese).

26. Yang F, Gu D. Predictability of frailty index and its components on mortality in older adults in China. BMC Geriatr. 2016;16:145. 
27. Zhang Q, Wu Y, Han T, Liu E. Changes in cognitive function and risk factors for cognitive impairment of the elderly in China: 2005-2014. Int J Environ Res Public Health. 2019;16(16):2847.

28. Park NS. The relationship of social engagement to psychological well-being of older adults in assisted living facilities. J Appl Gerontol. 2009;28:461-81.

29. Lei X, Bai C. Cognitive function and mental health of elderly people in China: findings from 2018 Clhls survey. China Popul Dev Stud. 2020;3:343-51.

30. Lei $X$, Sun $X$, Strauss J, Zhang P, Zhao Y. Depressive symptoms and SES among the mid-aged and elderly in China: evidence from the China health and retirement longitudinal study national baseline. Soc Sci Med. 2014;120: 224-32.

31. Li W, Wu M, Yuan F, Zhang H. Sugary beverage consumption mediates the relationship between late chronotype, sleep duration, and weight increase among undergraduates: a cross-sectional study. Environ Health Prev Med. 2018;23(1):63 Published 2018 Dec 22

32. Kuykendall L, Tay L, Ng V. Leisure engagement and subjective wellbeing: a meta-analysis. Psychol Bull. 2015;141:364-403.

33. Akaike H. Factor analysis and AIC. Psychometrika. 1987;52(3):317-32.

34. Schwarz G. Estimating the dimension of a model. Ann Stat. 1978;6(2):461-4.

35. Sclove SL. Application of model-selection criteria to some problems in multivariate analysis. Psychometrika. 1987;52(3):333-43.

36. Sparouhov T, Muthen B. Using Mplus TECH11 and TECH14 to test the number of latent classes. Paper can be downloaded from here. Mplus Web Notes: No. 14. 2012. Available online: http://www.statmodel.com/examples/ webnotes. Accessed 1 Aug 2020.

37. Kongsted A, Nielsen AM. Latent class analysis in health research. J Physiother. 2017;63(1):55-8.

38. Banks J, Nazroo J, Steptoe A. The dynamics of ageing: evidence from the English longitudinal study of ageing 2002-12 (wave 6). The Institute for Fiscal Studies; 2014.

39. Hung WW, Ross JS, Boockvar KS, Siu AL. Recent trends in chronic disease, impairment and disability among older adults in the United States. BMC Geriatr. 2011;11:47 Published 2011 Aug 18.

40. Cambois E, Blachier A, Robine JM. Aging and health in France: an unexpected expansion of disability in mid-adulthood over recent years. Eur J Pub Health. 2013;23(4):575-81.

41. Chen X, Orom H, Hay JL, Waters EA, Schofield E, Li Y, Kiviniemi MT. Differences in rural and urban health information access and use. J Rural Health. 2019; 35(3):405-17. https://doi.org/10.1111/jrh.12335 Epub 2018 Nov 16.

42. Zhang $X$, Dupre ME, Qiu L, Zhou W, Zhao Y, Gu D. Urban-rural differences in the association between access to healthcare and health outcomes among older adults in China. BMC Geriatr. 2017;17(1):151.

43. Beydoun MA, Popkin BM. The impact of socio-economic factors on functional status decline among community-dwelling older adults in China. Soc Sci Med. 2005:60(9):2045-57.

44. Drewes YM, den Elzen WP, Mooijaart SP, de Craen AJ, Assendelft WJ, Gussekloo J. The effect of cognitive impairment on the predictive value of multimorbidity for the increase in disability in the oldest old: the Leiden 85plus study. Age Ageing. 2011:40(3):352-7.

45. Connolly D, Garvey J, McKee G. Factors associated with ADL/IADL disability in community dwelling older adults in the Irish longitudinal study on ageing (TILDA). Disabil Rehabil. 2017;39(8):809-16.

46. Kalavina R, Chisati E, Mlenzana N, Wazakili M. The challenges and experiences of stroke patients and their spouses in Blantyre, Malawi. Malawi Med J. 2019:31(2):112-7.

47. Von Humboldt S, Leal I. Adjustment to aging in late adulthood: a systematic review. Int J Gerontol. 2014;8(3):108-13.

48. Rozanova J, Keating N, Eales J. Unequal social engagement for older adults: constraints on choice. Can J Aging. 2012;31(1):25-36.

49. Sone T, Nakaya N, Tomata Y, Hoshi M, Tsuji I. Functional disability among partners and community activity in elderly Japanese: the Ohsaki cohort 2006 study. Arch Gerontol Geriatr. 2018;78:150-4.

50. Himes CL, Reynolds SL. Effect of obesity on falls, injury, and disability. J Am Geriatr Soc. 2012;60(1):124-9.

51. Coin A, Sergi $G$, Benincà $P$, et al. Bone mineral density and body composition in underweight and normal elderly subjects. Osteoporos Int. 2000;11(12):1043-50

52. Tanaka S, Kuroda T, Saito M, Shiraki M. Overweight/obesity and underweight are both risk factors for osteoporotic fractures at different sites in Japanese postmenopausal women. Osteoporos Int. 2013;24(1):69-76 [published correction appears in Osteoporos Int. 2013 mar;24(3):1143-4].
53. Bahat G, Tufan F, Saka B, et al. Which body mass index (BMI) is better in the elderly for functional status? Arch Gerontol Geriatr. 2012;54(1):78-81.

54. Ćwirlej-Sozańska A, Wiśniowska-Szurlej A, Wilmowska-Pietruszyńska A, Sozański B. Determinants of ADL and IADL disability in older adults in southeastern Poland. BMC Geriatr. 2019;19(1):297.

55. Quiñones AR, Markwardt S, Botoseneanu A. Diabetes-multimorbidity combinations and disability among middle-aged and older adults. J Gen Intern Med. 2019;34(6):944-51.

56. MacNeilVroomen JL, Han L, Monin JK, Lipska KJ, Allore HG. Diabetes, heart disease, and dementia: National Estimates of functional disability trajectories. J Am Geriatr Soc. 2018;66(4):766-72.

57. Ormel J, Rijsdijk FV, Sullivan M, van Sonderen E, Kempen Gl. Temporal and reciprocal relationship between $I A D L / A D L$ disability and depressive symptoms in late life. J Gerontol B Psychol Sci Soc Sci. 2002;57(4):P338-47.

58. Gurland BJ, Wilder DE, Berkman C. Depression and disability in the elderly: reciprocal relations and changes with age. Int J Geriatr Psychiatry. 1988;3(3):163-79.

59. Lei $X$, Smith JP, Sun $X$, Zhao Y. Sex differences in cognition in China and reasons for change over time: evidence from CHARLS. J Econ Ageing. 2014;4:46-55.

\section{Publisher's Note}

Springer Nature remains neutral with regard to jurisdictional claims in published maps and institutional affiliations.
Ready to submit your research? Choose BMC and benefit from:

- fast, convenient online submission

- thorough peer review by experienced researchers in your field

- rapid publication on acceptance

- support for research data, including large and complex data types

- gold Open Access which fosters wider collaboration and increased citations

- maximum visibility for your research: over $100 \mathrm{M}$ website views per year

At $\mathrm{BMC}$, research is always in progress.

Learn more biomedcentral.com/submissions 